\title{
O PAPEL DA ENFERMEIRA, DA AUXILIAR DE ENFERMAGEM E DO ATENDENTE DE ENFERMAGEM NA ASSISTENCIA AO PACIENTE EM ISOLAMENTO DE DOENÇAS TRANSMISSIVEIS *
}

\author{
Elucir Gir ** \\ Tokico Murakawa Moriya***
}

GIR, E.; MORIYA, T.M. O papel da enfermeira, da auxiliar de enfermagem e do atendente de enfermagem na assistência prestada ao paciente em isolamento de doenças transmissiveis. Rev. Esc. Enf. USP, v. 25, n. 3, p. 271-86, dez. 1991.

Observadores previamente treinados, realizaram um levantamento das atividades instrumentais e expressivas desempenhadas por enfermeiras, auxiliares de enfermagem $e$ atendentes de enfermagem na assistência direta a pacientes portadores de doença transmissivel, internados em unidade de isolamento de um hospital geral. Concluiram que os membros da equipe de enfermagem realizaram maior número de atividades instrumentais do que expressivas; em termos numéricos, o atendente foi quem mais exccutou estas atividades, seguido do auxiliar de enfermagem $e$, por último, da enfermeira.

UNITERMOS: Enfermagem em doenças transmissiveis. Ocupacionais em enfermagem. Exercicio da enfermagem.

\section{INTRODUÇAO}

Grande número de doenças transmissiveis provavelmente existiam muito antes do homem habitar a terra. Com o progresso da civilização, o contato homem-homem favoreceu sua disseminação, provocando elevadas taxas de morbi-mortalidade em diversos paises, principalmente naqueles em desenvolvimento.

As concepçōes atribuídas a estas doenças têm sido modificadas através dos tempos, desde a crença em maus espíritos até a descoberta de microrganismos como causadores destas enfermidades (MORIYA; MANZOLLI, 1986).

Este embasamento científico deveu-se aos experimentos pioneiros de Pasteur, realizados por volta de 1870, os quais foram responsáveis pelo despontar e avanço da microbiologia. Já na Idade Média, surgiram as

* Trabalho realizado com auxilio-pesquisa fornecido pelo CNPq.

* Fnfermelra. Prolessor Assistento Junto ao Departamento de Enfermagem Geral o Ilspeclalizada du Feola de Bnfermagem de Ribelrăo Preto-USP.

*** Infermeira. Professor Doutor junto ao Departamento de Innfermagem Geral e FspeciaIizada da Frscola de Infermagem de Ribeirko Preto-USP. 
unidades de isolamento nos hospitais gerais ou especializados, onde procedimentos e técnicas específicas eram empregadas como uma das medidas para prevenção e controle das doenças transmissíveis. $\mathrm{Na}$ Biblia encontram-se, também, descrições sobre isolamento de leprosos e portadores de doenças venéreas (MORIYA; GIR, 1988). Os dados acima destacados nos indicam, portanto, quão remoto é o reconhecimento da importância das medidas de isolamento.

Apesar das doenças transmissíveis serem tão antigas, ainda hoje são carregadas de tabus e estigmas, além de algumas pessoas ainda considerarem 0 isolamento como local para segregação de indivíduos. Esta conotação deve ser abandonada, pois devemos é isolar o microrganismo e não o doente, conforme cita PALMER (1984).

NOVAES (1975) constatou que o processo patológico, pelas suas próprias características, pode levar o indivíduo a regredir emocionalmente, bem como a intensificar seu narcisismo e transferir seu afeto para pessoas do hospital. JOHNSON; MARTIN (1958), acrescentaram ainda um outro aspecto, ou seja, o surgimento de problema referente às necessidades humanas básicas.

Portanto, se a doença associada à hospitalização acarreta alterações que diferem em grau e intensidade de individuo para individuo, quando se trata de doença transmissivel este transtorno pode acentuar-se significativamente, a ponto de provocar desordens emocionais sérias, por mais equilibrada emocionalmente que seja a pessoa.

Têm sido observados, com freqüência, por enfermeiras que atuam na área de isolamento de doenças transmissiveis, pacientes com comportamento agressivo, tentativa de suicídio, depressão, anorexia profunda, apatia, desinteresse e outras manifestações (MORIYA; MANZOLLI, 1986).

KAMIYAMA (1979) enumera alguns comportamentos negativos apresentados pelos pacientes com hepatite durante a internação. São eles: revolta contra os regulamentos do hospital e a orientação médica e de enfermagem; fuga por rejcição ao tratamento recebido no hospital; recusa do tratamento no hospital e rebelião contra as ordens médicas e de enfermagem; agressividade entre pacientes, tanto com palavras como com ações; agressões à equipe de enfermagem, manifestadas por palavras e ações; tensão; detectadas através de expressão verbal, por excessiva preocupação com a demora de alta, acompanhada de agitação, tremores e choros frequientes; passividade excessiva, revelada pela não participação da vida da enfermaria; negativismo, sem agressividade ou revolta, manifestado pela recusa do tratamento no hospital.

Historicamente, a educação tradicional em enfermagem tinha como objetivo preparar o aluno para desempenhar um único papel, o de ser subordinado ao médico. Esse papel só incluia ações que se referiam a obedecter às ordens médicas, como, por exemplo, executar as suas prescrições, além de dar cuidados físicos ao paciente, alimentação, conforto (ALCÂNTARA, 1963). 
As grandes transformações ocorridas com o progresso da ciência e da tecnologia, as modificações dos conceitos de saúde e doença, o aumento da população mundial e o desenvolvimento dos meios de comunicação, entre outros fatores, naturalmente vieram influcnciar o conceito de doenças transmissíveis e de isolamento para essas enfermidades e, consequientemente, o papel desempenhado pelo pessoal de enfermagem na assistência ao paciente.

Segundo PARSONS; BALES (1955), apud JOHNSON; MARTIN (1958), a enfermeira desempenha dois papéis terapêuticos na assistência prestada ao paciente, ou seja, 0 papel expressivo ou básico e o papel instrumental ou técnico.

Não devemos nos esquecer ainda de que a "ação da enfermeira é dirigida às pessoas, entendidas como seres bio-psico-sociais, englobando noções de integração, equilibrio e adaptação, em relação a si, ao outro e ao seu ambiente" (MINZONI, 1976).

Somos de parecer que o paciente portador de doença transmissível, internado numa unidade de isolamento, requer apoio psicológico especial; necessita estar ciente do significado do isolamento, bem como dos procedimentos técnicos específicos utilizados nesta unidade.

Diante do exposto, propusemo-nos a realizar um levantamento das atividades instrumentais e expressivas desempenhadas pelas enfermeiras, auxiliares de enfermagem e atendentes na assistência direta aos pacientes portadores de doença transmissivel, internados em unidade de isolamento.

\section{DEFINIÇAO DE TERMOS}

- Atividade: Conjunto de tarefas, atribuições que explicitam as funções e que é exercida de maneira sistemática e reiterada em seu desempenho (CHIAVENATO, 1983, apud GIR et al., 1990).

- Papel: Conjunto organizado de comportamentos, que são ativados quando o indivíduo ocupa determinada posição, num contexto de papéis complementares (SARBIN; ALLEN, 1968, apud GIR et al., 1990).

- Atividade Instrumental: Atividade referente à realização, colaboração, orientação e supervisão de procedimentos técnicos.

- Atividade Expressiva: Atividade verbal ou motora relacionada à manutenção do equilíbrio "motivacional" do paciente.

- Equipe de Enfermagem: grupo de pessoas que trabalham unidas pelo objetivo comum de prestar assistência de enfermagem, sob a coordenação, orientação e supervisão do enfermeiro, e onde cada elemento sabe qual o papel a desempenhar, condizente com sua competência (SIMOEES, 1983). 
Os elementos da equipe de enfermagem que participaram deste estudo foram: enfermeira, auxiliar de enfermagem e atendente de enfermagem.

\section{METODOLOGIA}

O presente trabalho foi realizado na Unidade de Internação de Moléstias Infecto-Contagiosas de um hospital geral, do interior do Estado de São Paulo.

\section{- População}

Foi constituída por enfermeiras, auxiliares de enfermagem e atendentes de enfermagem do referido hospital e pacientes por eles assistidos.

\section{- Amostra}

Seis enfermeiras, sete auxiliares de enfermagem e sete atendentes de enfermagem, lotados na Unidade de Internação de Moléstias Infecto-Contagiosas da instítuição e 14 pacientes.

- Seleção dos sujeitos:

A seleção dos pacientes foi realizada aleatoriamente através de sorteio das enfermarias, ou seja, do total de nove enfermarias existentes para adultos, eram sorteadas diariamente três.

$\mathrm{Na}$ tentativa de termos uma visão geral das atividades desempenhadas pela equipe de enfermagem junto aos pacientes, foram estes selecionados aleatoriamente, sem distinção de cor, raça, estado civil, nível de escolaridade, sexo, nível sócio-econômico cultural, estado geral, nível de consciência e tipo de isolamento.

Quanto à equipe de enfermagem, foram incluidos todos os elementos que estavam em seu horário de trabalho no período para a observação, determinados pelos pesquisadores, e que entraram nas enfermarias sorteadas por designação da escala ou não.

\section{- Instrumento}

Utilizamos para registro das observaçōes o impresso que constitui o Anexo I.

\section{PROCEDIMENTOS}

\section{- Preparo de Campo}

Encaminhamos uma carta à Diretora da Divisão de Enfermagem do Hospital em estudo, expondo nossos objetivos e solicitando permissão para a realização desta pesquisa. Mediante parecer favorável iniciamos o trabalho. 
Foram treinados como observadores 11 enfermeiras, para as quais expusemos nossos objetivos e planejamento e revisamos os aspectos gerais concernentes a unidade de isolamento. A seguir iniciamos 0 treinamento propriamente dito que compreendeu três semanas, de 02 a 05 horas diárias de observação, perfazendo um total geral de 340 horas, e uma média individual de 30 horas.

Os observadores foram orientados quanto:

- identificação do paciente,

- conduta durante a observação,

- anotação de horário de entrada e saída da enfermaria, de cada elemento da equipe de enfermagem,

- atribuição de siglas ou códigos e de seu significado a cada elemento da equipe de enfermagem em observação,

- registro fidedigno de todas as atividades motoras realizadas pela equipe de enfermagem junto ao paciente,

- registro fidedigno de todas as atividades verbais como ocorreram. Exemplos: At.D $\rightarrow$ P: Sr. José, o senhor precisa tomar bastante água.

$P \rightarrow$ At. D: Ah, está bom. Vou tentar.

(Enf. coloca esfigmomanômetro no membro superior de $P$. e verifica PA).

Diariamente discutíamos com cada observador o relato descrito e as dificuldades encontradas durante a observação, bem como as dúvidas quanto à caligrafia.

Dois observadores, considerados inaptos para participarem da pesquisa, por apresentarem falhas de redação e anotação foram excluídos, passando, portanto, para nove o número destes participantes.

Procedemos à calibração dos nove observadores, onde escalávamos duplas para observarem simultaneamente o mesmo paciente. Calculamos o indice de fidedignidade das duplas, segundo fórmula adotada por BIJOU et al (1969), ou seja:

$$
\mathrm{IF}=\frac{\mathrm{n}^{\circ} \text { de acordos }}{\mathrm{n}^{\circ} \text { de acordos }+\mathrm{n}^{0} \text { de desacordos }} \times 100
$$

Iniciamos a coleta de dados, propriamente dita, ao obtermos indice médio igual a $87,11 \%$, indice este considerado satisfatório por CARVALHO (1979) e MENDES (1986). 
A observação foi realizada num periodo não letivo, durante cinco dias consecutivos, nos horários das 7:00 às 13:00 e das 13:00 às 19:00 horas (turnos manhã e tarde). A escolha deste horário foi baseada em MENDES (1986), que refere serem os períodos das 7:00 às 11:00 e das 13:00 às 17:00 horas aqueles em que ocorre o maior número de contatos e interações entre o paciente e a equipe de enfermagem.

Diariamente, três enfermarias eram sorteadas para observação; para esta, apenas um observador permanecia no interior de cada enfermaria.

Foi feito rodízio dos nove observadores de maneira a haver sempre um observador dentro de cada enfermaria sorteada, ao longo das 12 horas de observação; cada observador aí permanecia no máximo 3 horas diárias.

A técnica de observação do tipo "relato cursivo" e a técnica de "registro com lápis e papel" foram as utilizadas nesta pesquisa.

Para cada seis horas de observação, elaboramos um protocolo. Ao longo dos cinco dias obtivemos 28 protocolos, pois os de números $29 \mathrm{e}$ 30 foram excluídos pelo fato dos pacientes terem saído de alta e não termos completado o turno de seis horas de observação.

\section{- Análise dos dados}

As atividades instrumentais e expressivas foram subcategorizadas conforme descrição abaixo, pelos autores da pesquisa, com base na análise dos protocolos.

\section{A - Atividade instrumental: subcategorias}

1. Preparar medicamentos ou material

2. Realizar procedimentos técnicos (verificar sinais vitais, fazer catèterismo, etc.)

3. Colaborar ou discutir sobre procedimentos técnicos

4. Orientar procedimentos técnicos

5. Orientar sobre rotinas hospitalares, medicamentos, estado geral, higiene, preparos de exames

6. Executar medidas de conforto

7. Oferecer, orientar, ajudar ou questionar sobre alimentação, hidratação

8. Controlar eliminações

9. Executar procedimentos auxiliares (trocar frascos, trocar inampers, organizar a enfermaria, distribuir refeiçōes)

10. Supervisionar, observar ou orientar ações do funcionário ou paciente 
11. Dar ordens, direções (Ex.: "vou verificar a PA", "Abaixe o braço", "Voltarei depois")

12. Avaliar a evolução do paciente (Ex.: "Aperte a minha mão". "Está com fome"?)

13. Solicitar informações (Ex.: "Vocé colheu sangue"? "Por que tirou o esparadrapo"?)

\section{$B$ - Atividade Expressiva: subcategorias}

1. Promover entretenimento

2. Demonstrar solidariedade, afeto, compreensão

(Bom dia. Como está hoje?)

3. Demonstrar amizade, simpatia, respeito

4. Encorajar, elogiar, acalmar

5. Demonstrar colaboração, interesse. ("Está com frio"? "Quando precisar me chame". "O que está doendo"?)

6. Reprimir condutas

7. Manifestar impaciência.

Consideramos como uma atividade todo ato, ação verbal ou motora ou frase. Dois juizes foram treinados para classificar as atividades, contidas nos protocolos, em "instrumental" e/ou "expressiva" e suas subcategorias.

A partir daí, procedemos à análise quantitativa desses dados.

\section{RESULTADOS E DISCUSSÄO}

No presente estudo, foram obscrvados seis enfermeiras, sete auxiliares de enfermagem, todas do sexo feminino, e sete atendentes de enfermagem, dos quais quatro do sexo feminino e três do sexo masculino, enquanto desempenhavam atividades diretas junto a 14 pacientes portadores de doenças transmissiveis, internados em unidade de isolamento. No Quadro I apresentamos as caracteristicas pessoais e clínicas destes pacientes, identificados por letras.

Os dados obtidos em 168 horas de observação foram agrupados em 28 protocolos, que totalizaram 237 páginas. Destas, os juizes julgaram e extraíram 1837 atividades, sendo $1239(67,44 \%)$ instrumentais e 598 $(32,55 \%)$ expressivas (Tabela I).

As atividades instrumentais foram mais freqüentes que as expressivas, para todos os elementos da equipe de enfermagem.

Segundo BALES (1950), toda atividade instrumental é também expressiva, mas nem toda atividade expressiva é instrumental. Neste estudo, os juízes classificaram as atividades enquadrando-as numa categoria, levando em consideração a sua predominância, se instrumental ou expressiva. 


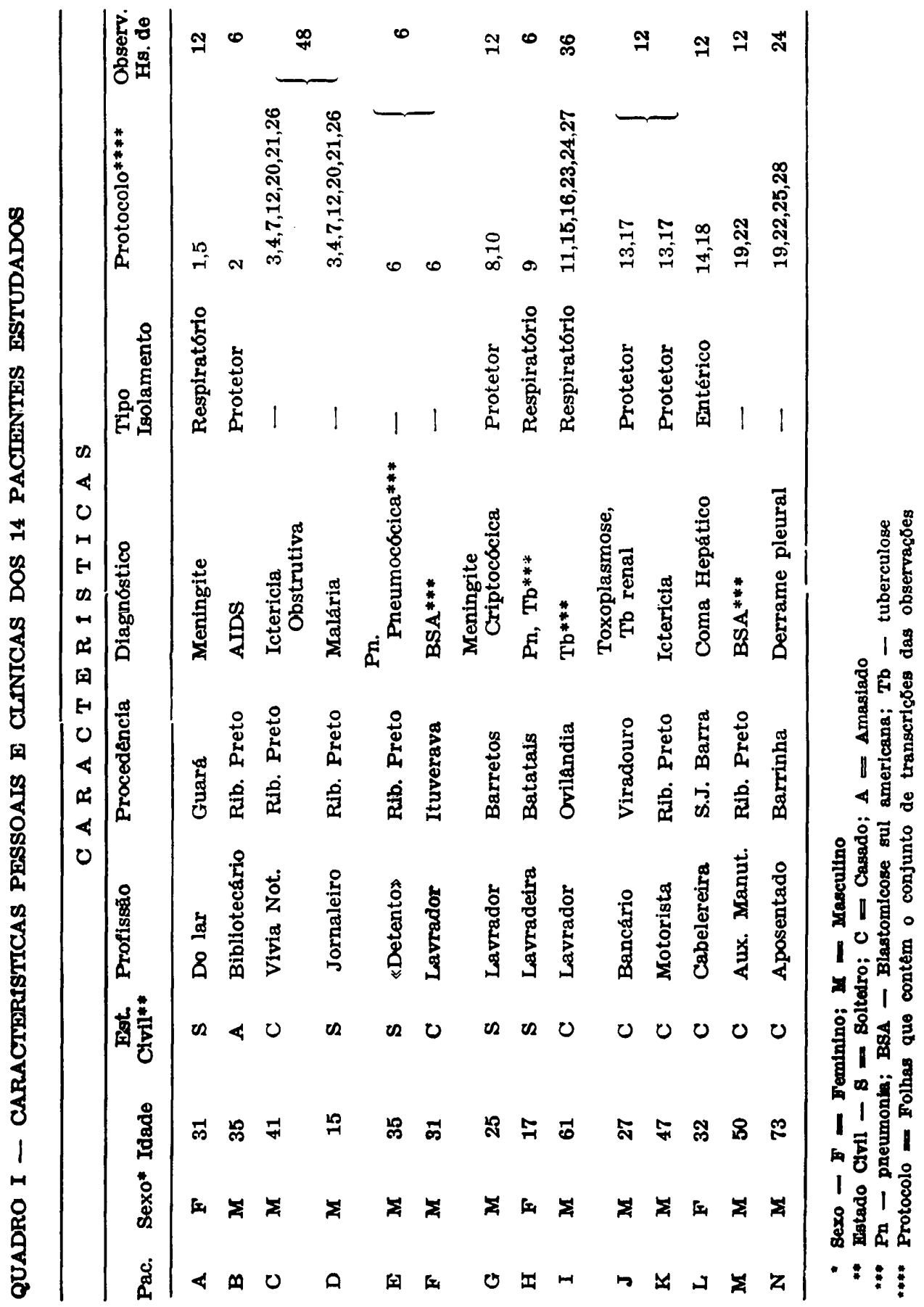


TABEIAA I - DISTRIBUICAO DAS ATIVIDADES INSTRUMMENTAIS E EXPRESSIVAS SEGUNDO CADA FMEMMENTO DA EXUIPE DE ENFERMAGEM

\begin{tabular}{|c|c|c|c|c|c|c|}
\hline \multirow{3}{*}{$\begin{array}{c}\text { Equipe } \\
\text { de } \\
\text { Enfermagem }\end{array}$} & \multicolumn{4}{|c|}{ Tipo de Atividade } & \multirow{2}{*}{\multicolumn{2}{|c|}{ Total }} \\
\hline & \multicolumn{2}{|c|}{ Instrumental } & \multicolumn{2}{|c|}{ Expressiva } & & \\
\hline & ne & $f(\%)$ & $n^{0}$ & $f(\%)$ & $n^{\circ}$ & $(\%)$ \\
\hline $\begin{array}{l}\text { Atendente de } \\
\text { Enfermagem }\end{array}$ & 671 & 70,32 & 241 & 29,67 & 812 & 100 \\
\hline $\begin{array}{l}\text { Auxdliar de } \\
\text { Innfermagem }\end{array}$ & 420 & 67,86 & 198 & 32,03 & 618 & 100 \\
\hline Finformetira & 248 & 60,93 & 159 & 39,06 & 407 & 100 \\
\hline $\mathbf{T} 0 \mathrm{t}$ a 1 & 1239 & 67,44 & 598 & 32,55 & 1837 & 100,00 \\
\hline
\end{tabular}

Em termos numéricos, os atendentes executaram maior número de atividades que as auxiliares e estas, maior número que as enfermeiras, tanto de atividades instrumentais como de expressivas. O número médio de atividades realizadas individualmente, em cada grupo de profissionais, demonstram o mesmo fato, ou seja, ao longo dos 5 dias de observação, cada atendente executou, em média 116 atividades, das quais 80 instrumentais e 36 expressivas, a auxiliar de enfermagem, 88 atividades, sendo 60 instrumentais e 28 expressivas, e a enfermeira, 68 , das quais 41 instrumentais e 27 expressivas.

O fato do maior número de atividades ter sido executado por atendentes e auxiliares de enfermagem talvez seja devido à modalidade de assistência empregada no referido hospital, que, segundo ÉVORA (1984), é a funcional; portanto, o atendente e o auxiliar de enfermagem cumprem escalas de serviço e a eles são delegadas tarefas principalmente de assistência ao paciente. À enfermeira, como líder da equipe de enfermagem, cabe, além da função assistencial, a supervisão e a administração dos cuidados prestados na unidade, o planejamento, a avaliação e a educação em serviço, ou seja, uma multiplicidade de funções.

TREVIZAN (1986), estudando a função administrativa da enfermeira nesta mesma instituição, menciona que "teoricamente tem sido apregado que a enfermeira deve dedicar-se à assistência direta aos pacientes e fazer dele o seu objeto de trabalho", e que "esta aspiração está refletida nas atribuições determinadas a esse profissional pelo Manual da Divisão de Enfermagem deste hospital"; demonstrou, contudo, que a enfermeira não chega a dedicar um quinto de seu tempo a essa função e acrescenta, ainda, que este dado sugere parecer persistir uma concepção, entre alguns enfermeiros da instituição, de que a função de assistência direta pode ser delegada.

Nas Tabelas II e III apresentamos, respectivamente, a distribuição das diversas subcategorias das atividades instrumentais e das expressivas, segundo cada grupo de elementos da equipe da enfermagem. 


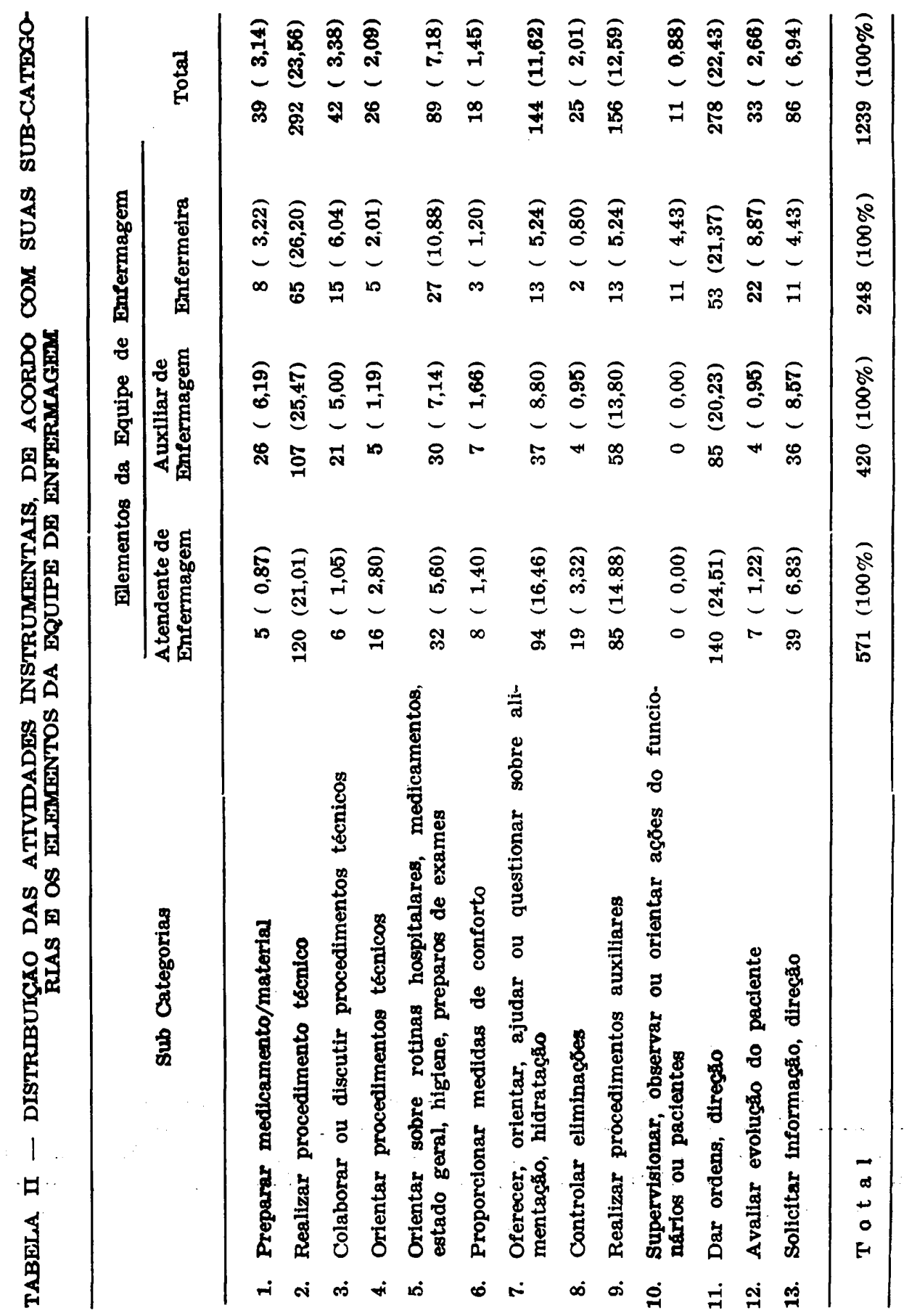




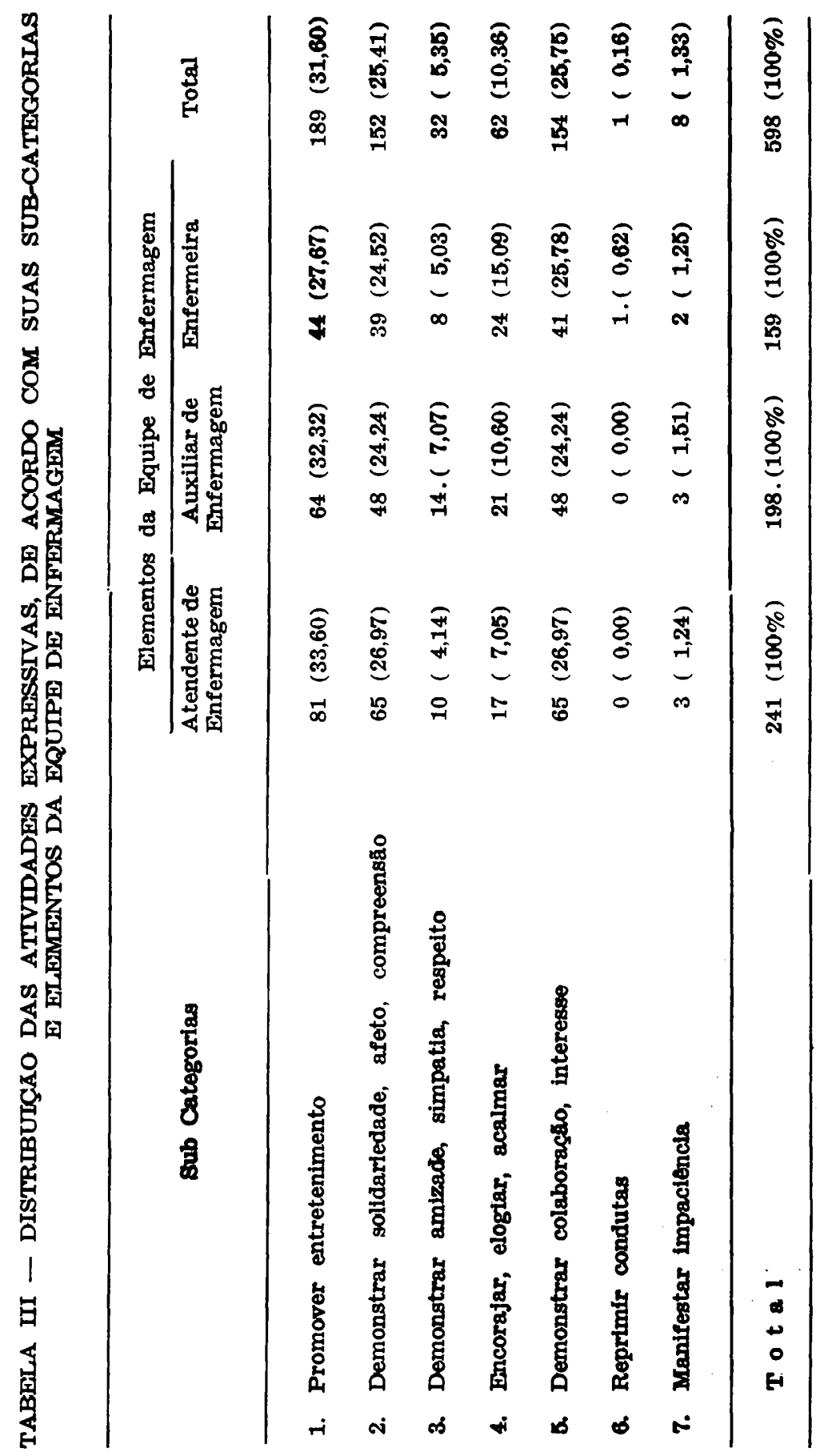


Analisando a Tabela II, podemos observar que, dentro das atividades instrumentais, as subcategorias mais freqüentes no conjunto foram: em 19 lugar, "Realizar procedimentos técnicos"; $2^{\circ}$, "Dar ordens, direções" e em 3, "Realizar procedimentos auxiliares".

Ao fazer a análise comparativa entre os grupos profissionais podemos observar que, apesar de todas as atividades - exceto "Supervisionar, Observar ou Orientar ações do funcionário ou paciente" - terem sido realizadas indistintamente por todos da equipe, determinadas atividades, em termos proporcionais, foram executadas mais por um grupo de profissionais do que por outro.

$O$ atendente de enfermagem executou mais as atividades "Oferecer, orientar, ajudar ou questionar sobre alimentação, hidratação" e "Controlar eliminações", do que a auxiliar e a enfermeira. A auxiliar de enfermagem execufou mais as atividades "Preparar medicamentos e/ou material" do que o atendente e a enfermeira; finalmente, a enfermeira atuou mais nas subcategorias "Orientar sobre rotinas hospitalares, medicamentos, estado geral, higiene, preparos de exames", "Supervisionar, observar ou orientar ações do funcionário ou paciente" e "Avaliar evolução do paciente".

Quanto à Tabela III, observamos que as três subcategorias da atividade expressiva mais freqüentes foram: 1") "Promover entretenimento", 2") "Demonstrar colaboração, interesse", e 3") "Demonstrar solidariedade, afeto, compreensão".

Como na Tabela II, o atendente de enfermagem é o elemento da equipe que realizou numericamente mais atividades expressivas, seguido da auxiliar de enfermagem e da enfermeira.

Ao fazer a análise comparativa entre os três grupos de profissionais, percebemos que as subcategorias da atividade expressiva também foram executadas, mais pelo atendente, em $2^{\circ}$ lugar pela auxiliar de enfermagem e em $3^{\circ}$ pela enfermeira, em termos proporcionais, exceto a subcategoria "Encorajar, elogiar, acalmar".

Segundo afirmamos em nossa Metodologia, extraimos, a partir dos dados contidos nos protocolos da observação realizada pelos observadores, tanto as subcategorias que podem contribuir positivamente para a manutenção do equilíbrio motivacional, como aquelas que podem contribuir para o desequilíbrio do individuo. As subcategorias de números 1 a 5 refletem atividades expressivas positivas, enquanto que as de números 6 e 7 refletem as negativas.

Consideramos favoráveis os dados aqui apresentados, uma vez que das 598 atividades expressivas julgadas nos protocolos, 589 (98,49\%) foram positivas e apenas $9(1,50 \%)$ negativas.

A predominância de aspectos positivos no relacionamento interpessoal é desejada na interação com qualquer tipo de paciente, mas quando se trata de paciente internado em unidade de isolamento, a importância deste aspecto se acentua; considera-se que, conforme elucidam MO- 
RIYA; MAÑZOLLI (1986), isolamento é a "situação ambiental em que os estímulos oferecidos ao paciente são restritos e, neste caso, são poucas as oportunidades para que ele venha a emitir suas respostas operantes, importantes para manter seu equilibrio psico-social. Ao mesmo tempo é uma situação que elicia respostas respondentes de cunho emocional".

Para JOHNSON; MARTIN (1958), a enfermeira é o especialista expressivo em primeiro lugar e especialista instrumental secundariamente. Nesse estudo, o número de atividades instrumentais desempenhadas pela enfermeira e pela equipe de enfermagem, como um todo, superou as atividades expressivas. No entanto, vale ressaltar que estes resultados são provavelmente, devidos ao fato de, no momento da análise, os juizes terem enquadrado cada atividade numa só categoria, segundo a sua predominância, embora nas atividades instrumentais estivessem presentes, também, componentes expressivos, em menor grau.

\section{CONSIDERAÇOES FINAIS}

O presente estudo mostrou-nos que a enfermeira, a auxiliar de enfermagem e o atendente de enfermagem ao desempenharem seus papéis junto a pacientes portadores de doenças transmissiveis, internados em unidade de isolamento, executaram maior número de atividades instrumentais $(67,44 \%)$ do que expressivas $(32,55 \%)$; sendo que, em termos numéricos, o atendente foi quem mais executou estas atividades, seguido do auxiliar de enfermagem e da enfermeira.

Comparados os três grupos de profissionais em termos proporcionais - o atendente de enfermagem realizou mais atividades relacionadas a "Oferecer, orientar, ajudar ou questionar sobre alimentação, hidratação" e "Controlar eliminações", a auxiliar de enfermagem executou mais tarefas referentes a "Preparar medicamentos e/ou material" e a enfermeira desempenhou atividades relativas a "Orientar sobre rotinas hospitalares, medicamentos, estado geral, higiene, preparos de exame", "Supervisionar, observar ou urientar ações do funcionário ou paciente" e "Avaliar evolução do paciente".

Quanto às subcategorias mais freqüentes da área expressiva, proporcionalmente, destacamos a subcategoria "Encorajar, elogiar, acalmar", realizada mais pela enfermeira, tendo as outras subcategorias sido desempenhadas de forma semelhante por todos os elementos da equipe de enfermagem.

Somos de parecer que na assistência direta prestada ao paciente, as atividades instrumentais são tão relevantes quanto as expressivas. De maneira geral, os resultados obtidos demonstram que a equipe de enfermagem vem atuando positivamente para manter o equilíbrio "motivacional" dos pacientes e levam a crer que a assistência prestada ao paciente e a formação profissional do pessoal são adequadas, destacando-se a educação continuada oferecida pela instituição aos seus funcionários. 
GIR, E.; MORIYA, T.M. The nurse's and nurse's aides role in caring the patient in a communicable disease isolation unit. Rev. Esc. Enf. USP, v. 25, n. 3, p. 271-86, Dec. 1991.

The instrumental and expressive activities performed by nurses and nurse's aides in the caring given to patients carrier of communicable diseases and that were ho:;italized in an isolation unit of a general hospital were surveyed. The authors concluded that nursing team performed more instrumental activities than expressive $o$ 'es the nursing attendant was one who did the higher number of the first activities, followed by the nursing auxiliary and the nurse.

UNITERMS: Nursing in communicable diseases. Nurse's aides. Nurses role.

\section{REFERENCIAS BIBLIOGRAFICAS}

ALCANTARA, C. A enfermagem moderna como categoria profissional: obstáculos à sus expansão na sociedade brasileira. Ribeirão Preto, 1963. 125p. Tese (Cátedra) - Escola de Enfermagem de Ribeirão Preto, Universidade de Săo Paulo.

BALLES, R.F. Interaction process analysis: a method for the study of small groups. Cambridge, Addison - Wesley Press, 1950.

BIJOU, S.W.; PETERSON, R.F.; HARRIS, F.R.; ALLEN, K.E.; JOHNSTON, M.S. Methodology for experimental studies of young children in natural settings. Psychol. Rec., v. 19, p. $177-210,1969$.

CARVALHO, E.C. Comportamento verbal o enfermagem: a interação verbal enfermeiro-paciente durante o procedimento de punção venosa. Ribeirâo Preto, 1979. 110p. Dissertaçăo (Mestrado) - Escola de Enfermagem de Ribeirão Preto, Universidade de São Paulo.

CHIAvejato, I. Recursos humanos. São Paulo. Atlas, 1983.

EVORA, Y.D.M. A propósito do trabalho de equipe no serviço de enfermagem. Rev. Paul. Hosp., v. 32 , n. $1 / 2$, p. $37-40,1984$.

GIR, E.; CARVAlho, E.C.; FERRAZ, A.E.P. Funcão e papel: estudo da terminologia. Rov. Gaúcha Enf., v. 11, n. 1, p. 11-17, 1990.

JOHNSON, M.M.; MARTIN, H.W. A sociological analysis of the nurse role. Am. J. Nurs., v. 58, n. 3, p. $373-377,1958$.

Kamirama, Y. Assistência centrada na identidade social: aspectos psico-sociais do cuiđado de enfermagem ao paciente de hepatite infecciosa. São Paulo, 1979. 191p. Tese (Livre Docência) - Escola de Enfermagem, Universidade de Sťo Paulo.

MENDES, I.A.C. Interaç̃o verbal em situaç̃es de entermagem hospitalar: enfoque humanistico. Ribeirão Preto, 1986. 175p. Tese (Doutorado) - Escola de Enfermagem de Ribeirão Preto, Universidade de Săo Paulo.

MINZONI, M.A. Uma conceltuaçăo de enfermagem psiquiátrica. Ene. Novas Dimens., v. 2, n. 5, p. 272-280, 1976.

MORIYA, T.M.; GIR, E. Isolamento em doenças transmissíveis. Ribeirăo Preto - Escola de Enfermagem de Ribeirão Preto, Universidade de São Paulo, 1988. (Mimeografado).

MORIYA, T.M.; MANZOLLI, M.C. Isolamento em doencas transmissfveis: conceituacão em Enfermagem. Rev. Esc. Ent. USP., v. 20, n. 2, p. 89-100, 1986.

NOVAes, M.H. Psicologia aplicada à reabilitacão. Rio de Janeiro, Imago, 1975.

PALMER, M.B. Infoction control: a policy and procedure mannual. Philadelphia, W.B. Saunders, 1984. 
PARSONS, T.; BALBS, R. Family socialization and interaction proceas. Chicago. Free Press, 1955.

SARBIN, T.R.; ALLEN, V.L. Role theory. In: LINDZEY, G.; ARONSON, E. The handbook of social psycholal gy. 2. ed. Cambridge, Addilson - Wesley, 1968. v.3, p.488-567.

SIMÖES, C. Glossário de enformagem. Rlo de Janeiro, Atheneu, 1983.

TREVIZAN, M.A. A lunç̃o administrativa da onformeira da instituição hospitalar burocratizada. Ribeirăo Preto, 1986. 200p. Tese (Doutorado). Escola de Enfermagem de Ribe1răo Preto, Universidade de Săo Paulo.

Recebido 25-7-90 
ANEXO I:

TMPRESSO PARA REGISTRO DAS OBSERVACOES

Data:........................... Observadora:.

Tipo de isolamento:

Folha: Paciente:

Registro:

Enfermeira :

Leito:

Periodo de observaçăo:

Inficio:

Término:

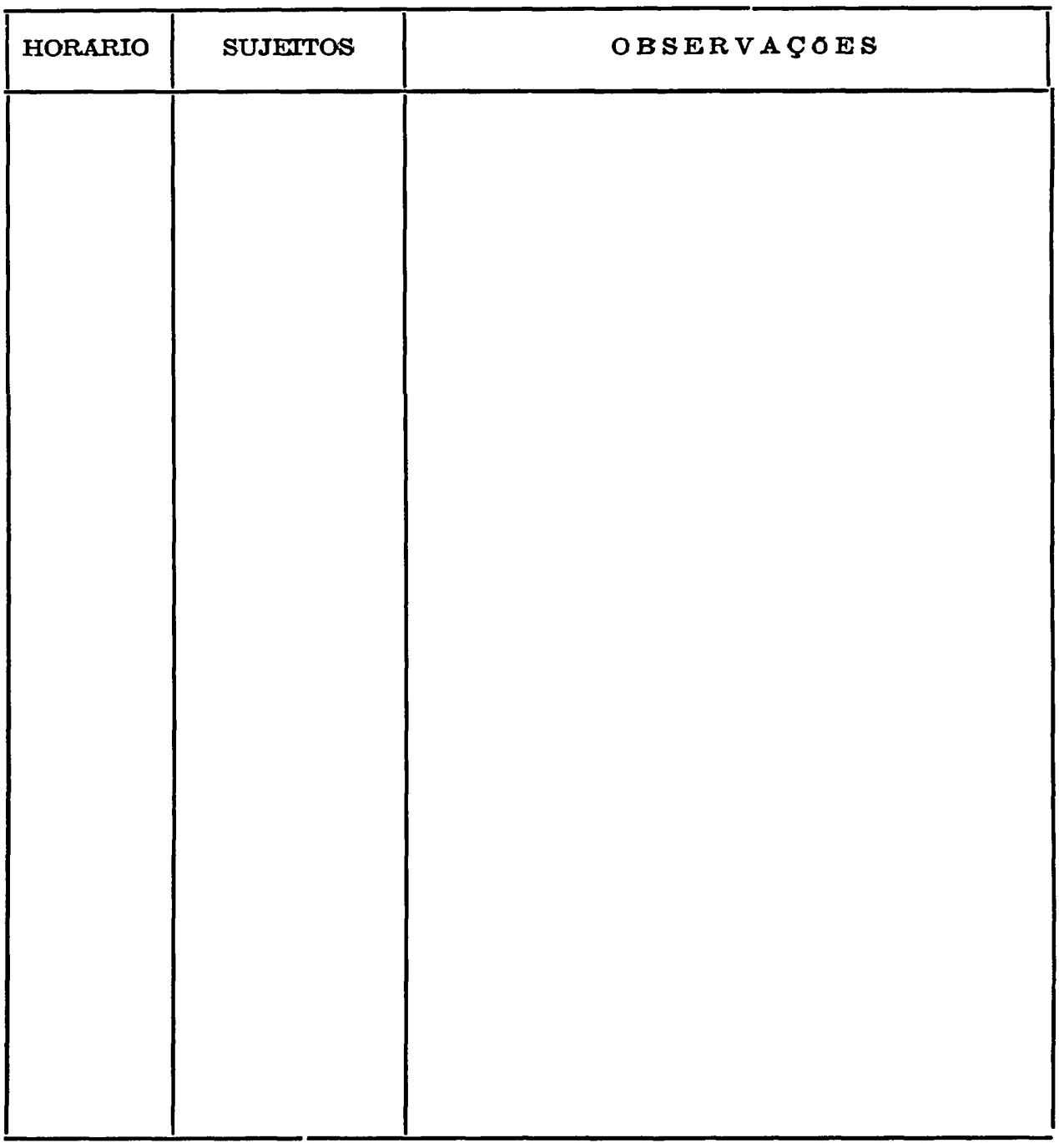

